\title{
Effect of teamwork culture on NPD team's capability in Indian engineering manufacturing sector
}

\author{
Sudeshna Roy ${ }^{a}$, Pranab K. Dan ${ }^{\mathrm{b}}$ and Nipu Modak ${ }^{\mathrm{a}^{*}}$
}

${ }^{a}$ Jadavpur University, India

${ }^{b}$ IIT Kharagpur, India

\section{H R O N I C L E}

\section{Article history:}

Received: March 13, 2018

Received in revised format:

March 13, 2018

Accepted: May 16, 2018

Available online:

May 17, 2018

Keywords:

New product development

NPD team's capability

Concurrent engineering team

Communication Infrastructure

System integration

Structural equation modeling

\section{A B S T R A C T}

Teamwork, for competitive advantage, involving techno-socio-cultural aspects of organizations for engineering developments, is gaining importance rather rapidly due to advent of globalization. The purpose of this study is to identify the importance of teamwork culture for new product development (NPD) success through enriching the NPD team's capability in Indian manufacturing industries. It accumulates the teamwork culture dynamics and practices, their interrelationships and their combined impact on NPD team's capability in terms of technological developments for NPD success. This practical analysis collects primary data from 263 design and development experts from Indian engineering manufacturing companies. Structural equation modeling (SEM) approach is applied to investigate the interrelationship among associated variables of teamwork culture and NPD team's capability for NPD success. Concurrent engineering team (CET), communication infrastructure (CI), system integration (SI) and result orientation (RO) have been recognized as allied factors of teamwork culture. Successful adoption of associated variables ensures NPD success through influencing NPD team's capability which in turn articulated by technological developments. The realization of combined impact of teamwork and its allied variables escalates technological developments which in turn enriches NPD team's capability assuring organizational success. The result indicates that both CI and SI support CET for accelerating NPD team's capability through technological developments. Besides, CET motivates innovation orientation most precisely referred as RO for escalating NPD team's capability through technological developments for innovation.

\section{Introduction}

The progression of globalization leads to social, cultural and political linkage worldwide making industrial success and sustainability uncertain. Technological innovation upgrades organizational innovativeness through new product development (NPD) (Nikakhtar et al., 2014; Nagano et al., 2014; Parthasarthy \& Hammond, 2002). This evolves the companies to produce new ideas and strategies for securing their future prospect. Though continuous improvement is a difficult task to be performed (Hailu et al., 2018) but NPD is an effective way for revitalizing the success of the firm by providing new products with the features as per the customers' demand (Bhuiyan, 2011). From NPD strategy to commercialization there are numerous factors influencing the ultimate growth of the firm by performing innovative activities (Chen et al., 2014; Azad et al., 2013; De Sousa Mendes \& Ganga, 2013). Difference in social, economic

* Corresponding author. Tel.: +91-9883088250

E-mail address: nmechju@gmail.com (N. Modak)

(C) 2018 by the authors; licensee Growing Science, Canada doi: $10.5267 /$ j.msl.2018.5.009 
and political atmosphere of various countries and varieties of industries make the difference in factors controlling the NPD performance. Indian economy is classified in three sectors such as agriculture, industry and service. Among these, industry is the second largest sector with percentage share of $29.02 \%$ and Gross Value Added (GVA) of Rs. 39.90 lakh crore INR in 2016-17. Manufacturing sector is the main contributor of the industry sector with percentage share $16.57 \%$ and GVA of Rs. 22.78 lakh crore INR in 2016-2017. The significance of manufacturing sector in Indian economy is unquestionable. Identification of critical factors for the success of Indian manufacturing industries is also undoubtedly imperative for economic growth of India.

Organizations embodying enriched culture generally value systems with strong beliefs leading to a society with acceptable behaviours (Early, 2006). Culture is a well-defined term as shared views of a group of people about priorities and building appropriate attitudes towards required developments (Varner \& Beamer, 2005). Organizational culture motivates the innovative behaviour by creating a strong commitment among the members of an organization leading towards a vivid teamwork culture in terms of believing in innovation as an organizational value (Mazzarol, 2002; Hartmann, 2001; Rodríguez-Pinto et al., 2012). The performance of the team can justify the probability of achieving goals in all aspects including NPD (Hoegl et al., 2003). Teamwork is the cooperation among employees of different functions essential for organizational sustainability (Felekoglu et al., 2013). Though talent, experience and skill are essential but the lack of teamwork culture that is working with the dissimilar people embracing the unfamiliar situation for organizational benefit arise conflicts. Teamwork behavior (Rousseau et al., 2006), team climate for innovation (Bain et al., 2003) for team performance have been discussed in the available researches. Teamwork culture leads to the positive outcomes beneficial for team performance for innovation (Strubler \& York, 2007). For developing team based culture, synchronization of the functional groups is essential for continuation of concurrent activities of the firm (Cleetus, 1992). Allocation of required resources for NPD needs to be carried out for simultaneous interdependent activities of groups which develop an environment of concurrent engineering (CE) (Chen et al., 2013). Sharing information and ideas are the best way to achieve higher concurrency level among interdisciplinary groups which can be achieved through meetings with different teams as per regular basis (Mousavi \& Darvishi, 2014). This cut down the probability of risks in CE as well as product development (Choi \& Ahn, 2010). Moreover, knowledge sharing is a necessary cultural phenomenon which requires building the teamwork culture within the organization to synchronize between the existing culture and the developing culture for organizational success (Friesl et al., 2011). Cross-functional team (CFT) offers harmonization among team members to overcome conflicts and differences occurred during the project completion (Green et al., 2000). The cross-cultural differences among the teams affect the success of the innovation oriented projects (Ghauri \& Rosendo-Rios, 2016). Entrenched relationships of top managers of CFT with team members helps in resolving conflicts, which could occur within the team (Anthony et al., 2014) and motivates to develop innovative products (Hartmann, 2001) through concurrent development activities. The collaboration among the interdisciplinary teams proposes better team performance utilizing the diverse team qualities (Saji, 2004). In interdisciplinary team culture, managers' activities mediate the functional heterogeneity among the teams for team effectiveness (Benoliel \& Somech, 2014). The concurrent engineering team (CET) with cross-functional activities develops a suitable environment for NPD. But there is a virtual barrier between the different teams working in a firm which can only be bridged through interactions and communication heading towards cooperative teamwork (Felekoglu et al., 2013). Proper integration among CET can be attained by providing proper communication infrastructure (CI) which helps in decision making as well as problem solving in challenging situations. Communication is a type of internal collaboration where information and idea sharing take place for better IPD performance (Everett et al., 2002). Concrete infrastructure for communication helps in bridging the functional teams for optimal use of individual competencies. Sustainability of innovative product development is conquered through optimal utilization of the organizational resources and existing skills (Tushman \& Anderson, 1997). Including the obtainability of system competencies, integration of these competences are correspondingly important for NPD success (Hitt et al., 2000). There is a need of clear governance of organizational systems including integration with strategic objectives and structuring of work teams (Nagono 
et al., 2014). Result orientation (RO) popularly termed as strategic orientation of a firm is a combination of innovation orientation and market orientation where innovation orientation is the technological dominance. This enhances the new product success in terms of profitability and sales growth (Augusto \& Coelho, 2009; Crawford \& Di Benedetto, 2000; Atuahene-Gima et al., 2005). Result orientation defines by interrelationship of time, costs, quality, people and organization for assuring better NPD performance.

Teamwork culture among the organization helps to socialize the creativity of the team members for technological innovations. This helps to develop products that are fundamentally different for creating competitive advantage (Hoegl \& Parboteeah, 2007). Attaining the desired cost, quality and time objectives of the newly developed products offer enriched team performance (Lechler, 1997) essential for product innovation. Efficiency and effectiveness are the ultimate matter of concern for quantifying team performance and its effect on NPD (Hoegl \& Parboteeah, 2003). For the present study, NPD team's capability has been considered as the constituent for measuring NPD success and technological developments are the manifest variables for quantifying the NPD team's capability for engineering development of the organization. This approach connects the effectiveness of teamwork culture as an organizational aspect which escalates NPD team's capability through technological developments of the innovative products ensuring the NPD success. The role of all the variants of teamwork culture in a firm is undoubtedly important but their implementation in practical field is somehow challenging due to presence of obstacles and difficulties created in internal and external ambience. Though the existence of the teamwork factors existed in the previous literatures but was not comprehensively explained in a single framework. Besides, the effort of linking these factors for the sake of NPD is also unnoticed. This framework is a novel approach towards the successful developments of innovative products.

The research adds originality by identifying the gaps and adding up the features: (1) development of comprehensive interrelationship model concerning all the variants of teamwork culture for enhancement of NPD team's capability as technological developments; (2) consideration of implementation perspectives of teamwork based variants in practical scenario; (3) exploration of teamwork culture in Indian manufacturing industries using the primary data base from design and development experts; (4) finally and most importantly, realizing the need for teamwork culture among multidisciplinary teams and groups within the organization for NPD team's capability in terms of technological developments fostering for innovation. This paper is clustered as follows: the next section provides a theoretical background of teamwork culture based practices for NPD team's capability and builds an interrelationship model based on developed hypotheses on the basis of that background including a path model depicting the teamwork culture based practices and their effects on NPD team's capability and ultimately on NPD success quantified by technological developments. Section 3 incorporates the detailing of research methodology including research objectives, measures and their analysis, sample and data collection from Indian manufacturing companies. Results and discussions section covers analysis of measurement validity, hypotheses testing and SEM model developed by using IBM SPSS AMOS 21.0 software packages. Ultimately, section 5 concludes the research with the theoretical as well as managerial insights from the findings of this study.

\section{Theoretical Background and Hypotheses Development}

Teamwork culture requires an environment that fosters learning, creativity and innovation for NPD (Estrada et al., 2013). Though the teamwork practice is established as critically vital for NPD success, the identification of all constituents of this practice and their interrelationships are being untouched. At the same time, their effects on NPD team's capability in terms of technological development for NPD success are also unidentified as per best knowledge. Derivation of two streams of theory sources develops the main theoretical basis of the study: (1) identification of constructs of teamwork based practices, (2) interrelationships of these constructs and their impact on NPD team's capability for achieving NPD success. Based on this theoretical background hypotheses have been developed to construct the interrelationship model. 


\subsection{Effect of concurrent engineering team (CET) on NPD team's capability \& result orientation (RO)}

Concurrent engineering team (CET) is a group of members associated with the CE practice for developing products within the scheduled time. CE is the method of performing the processes of the firm concurrently for reducing development time of the product to attain competitive advantages. The development time gets reduced as the planning, designs, manufacturing all are occurring in parallel manner associating the uncertainties in interdependent processes. In case of CE the multidirectional exchange of information, decision making, and data sharing among various functional groups take place for developing economic products within estimated time more easily and efficiently (Choi \& Ahn, 2010). CET introduces the idea of CFT culture which is the nature and attitude of working together among team members which again helps in developing sharing quality and the nature of problem solving together which is one of the most positive approach of the firm for achieving success (DeVries et al., 2006). Researchers identified that for NPD the planning and concurrency it is essential for problem solving by cross-functional integration (Aronson et al., 2006). Adoption of CET culture motivates the concurrency in NPD processes for enhancing NPD team's capability. CET ensures cooperation, trust and sharing among teams for developing products concurrently in a synchronous manner to achieve NPD success. CET offers integration of various functional groups to overcome the functional barriers and difficulties for strategic orientation among the team members for innovation (Berthon et al., 2004) which can be better stated as a result of orientation. The assumptions from the above discussions can be drawn that:

Hypothesis 1a (H1a): CET has a positive effect on NPD team's capability of the firm.

Hypothesis $1 b$ (H1b): The efficiency of CET enhances the RO among the NPD teams.

\subsection{Effect of communication infrastructure (CI) on NPD team's capability \& concurrent engineering team (CET)}

Teamwork is a firm's practice of working together with various functional groups to overcome problems arises in each step and successfully develop new products. The best way of achieving success is communication and interaction among the various teams (Kleinsmann et al., 2010). CI is one of the main features of internal as well as external integration for NPD (Johnson \& Filippini, 2013). Bi-directional communication approach always encouraged the ideas and information flow from senior management to employees and vice versa (Felekoglu et al., 2013). Usefulness of CI policy for NPD team's performance has been recognized by researches (Frishammar et al., 2012; Tsai et al., 2011). Communication enhances the better cooperation, coordination, sharing of information among teams leading towards better decisive capability of the teams in the firms under difficult conditions (Poole \& Hirokawa, 1996). CI has a salient bond with another vital constituent of teamwork culture which is CET. The CET quality is closely associated with the excellent communication culture among the teams to complete the task uninterruptedly (Kennedy et al., 2011). Enriched coordination among CET lowers the communication barrier among teams and helping to circulate information which accelerates better decision making ability (Anthony et al., 2014). From the above discussions the statements can be drawn:

Hypothesis 2a (H2a): A better CI increases the probability of NPD team's capability.

Hypothesis $2 b$ (H2b): The efficiency of CET will be enhanced by strong CI among the team members.

\subsection{Effect of System Integration (SI) on NPD team's capability, CET and RO}

System integration (SI) is the incorporation of resources of several functional groups for efficient development of innovative products. There are various types of required resources for development of products. The integration category differs depending on the types of resources available. Knowledge is one of the resources essential for NPD team's capability for innovation. Accumulation of internal and external knowledge for innovative product development helps to achieve the competitive advantage (Gu et al., 2011). In practical field, integration of internal capabilities such as various functional groups working 
together and the external relations like supplier and customer involvement are equally imperative for NPD success (Johnson \& Filippini, 2013). The effective integration of ideas, strategies, operational activities and commercialization procedure leads to the success of innovative product development (Sun et al., 2012). The very early stage of NPD consists of idea, screening and implementation phases which must be performed concurrently and as per time passes, these stages have been concurrently changed based on the practical environment (Nihtila, 1999). There are a number of researches concerning the integration of various types of systems such as integration in the manufacturing systems (Lindstrom \& Winroth, 2010), integration of cross-functional teams, integration of R\&D activities, and integration in system level and production level (O'Sullivan, 2003; Song et al., 2007). This integration accelerates NPD team's capability for achieving success. Besides, integration of various systems associated with NPD activities motivates strategic orientation of the firm ensuring technological developments. It correlates time, costs, quality, people and organization for better innovative product development activity. The implications from this discussion can be set that:

Hypothesis 3a (H3a): An effort of SI escalates the NPD team's capability of the firm.

Hypothesis $3 b$ (H3b): SI motivates CET culture of the firm.

Hypothesis3c (H3c): SI positively encourages RO among the NPD teams within the firm.

\subsection{Effect of Result Orientation (RO) on IPD success and system integration (SI)}

Result orientation (RO) is practically the strategic orientations consisting of innovation and market orientation (Chou \& Yang, 2011). The innovation orientations convey the technological improvements whereas, market orientation is the identification of customer need to develop new products as per demand. The effective interfaces between these two types of orientations can be achieved by integration among the employees of various functional groups of the firms to overcome the functional barriers and difficulties (Berthon et al., 2004). This may be explained as the strategic orientation among the quality, cost, time, people and organization for enhancement for better NPD success through enhancement of NPD team's capability. The above discussion signifies that:

Hypothesis 4 ( $\mathrm{H} 4 \mathrm{a}$ ): The betterment of RO motivates the NPD team's capability of the firm.

The insufficiency of the empirical researches in previous literatures to recognize and develop a comprehensive framework by considering the teamwork practices in Indian scenarios and by collecting the valuable responses from engineers of manufacturing industries of various parts on India creates a need to do this research. Moreover, the implementation of teamwork culture in small and medium enterprises in India is not satisfactory due to the socio economic structure (Leitner, 2011). This attitude leads to the decay in future growth due to incompetence with respect to the global perspective. This research is an effort to develop a comprehensive structural model depicting teamwork culture to achieve NPD success through enriching NPD team's capability by alarming the need of this practice in Indian manufacturing industries. Fig. 1 represents the path model of interrelationships of the teamwork culture based constructs and their impacts on escalating NPD team's capability for NPD success.

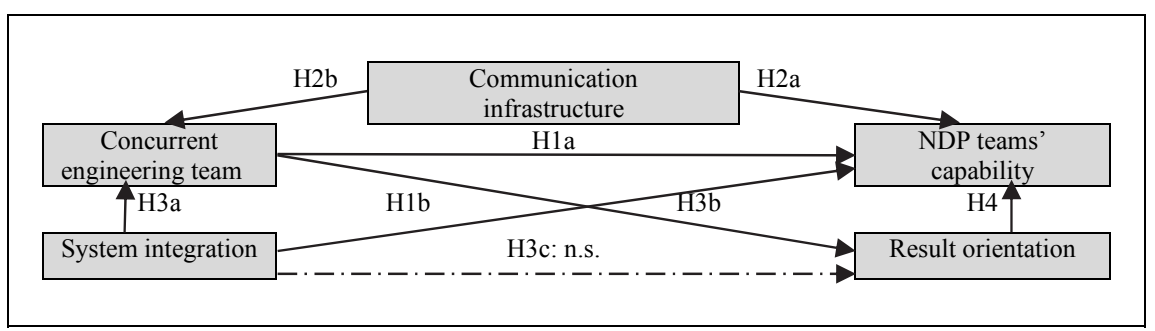

Fig. 1. Path model of constructs depicting combined effect of teamwork and its associated factors on NPD team's capability 


\section{Method}

Significance of incessant NPD practice of the firm for sustaining in global competitive environment is an established statement. There are number of theoretical and empirical researches regarding this fact. Teamwork as an organizational perspective mobilizes the innovative developments by enriching the team's capability for enhanced engineering activities. The close association of teamwork culture in governing the new product success is also inevitable. This study fulfills the gap in the research of NPD by accumulating the factors involved in articulating the teamwork culture of the firm to structure a model involving these teamwork based on the success factors and the NPD team's capability for technological developments within scheduled timeframe as success measures. A semi-structured questionnaire is formed and primary data is collected from design and development engineering experts of Indian manufacturing companies.

\subsection{Aim of the research}

The main aim of this research is identification of teamwork practice based success factors from theoretical background of the available literatures. After this recognition, the determination of the importance of these teamwork constituents based on the experts' opinions from Indian manufacturing industries is the foremost objective of this study. At the same time, the additional manifest variables used to quantify identified success factors which are not previously recognized in the available researches are assimilated for attaining more precise and detailed measurement. Furthermore, the degree of implementation of these factors in the firm by overcoming the practical obstacles is framed using the real-life data collected from the market survey. Finally, the role of technological developments based success measures in quantifying NPD team's capability for NPD success is established depending on the empirical survey in Indian manufacturing industries.

\subsection{Formation of questionnaire}

This exploratory research needs to develop a semi-structured questionnaire for gathering detailed ideas about the success factors associated with teamwork culture and technological developments for measuring NPD team's capability for final model formation. This questionnaire includes perspectives, importance and implementation of the factors, at the same time the idea of introducing unexplored manifests of the success factors for describing and quantifying the constructs more precisely. Few quarries mentioned in the questionnaire required for final model formation are listed:

(i) Is the teamwork culture essential for NPD team's capability of an organization?

(ii) What are the success factors/constituents related to teamwork culture of the firm?

(iii) How do these identified factors, such as CET, CI, SI and RO, affect the NPD team's capability in turn for the NPD success?

(iv) Is there any interrelationship among these factors?

(v) Whether technological developments in scheduled time are considered to express NPD team's capability of the firm for engineering developments?

(vi) What are the manifests required to quantify the success factors and success measures?

(vii) Degree of importance success factors as per the experts' opinion.

(viii) Degree of implementation of success factors based on the real-life scenario.

(ix) State the degree of technological developments is identified as success measures to describe the NPD team's capability of the firm. 
Using these quarries, a questionnaire comprising of both, one end and closed end portions, has been framed for accumulating experts' opinion and suggestions. The closed end portion gathers the information regarding the degree of importance and implementation using Likert scale, whereas, in open end section the provision for providing suggestions of experts about the manifests which can be used to quantify the factors is given for addition of more practical dimensions.

\subsection{Methodology}

Structural equation modeling (SEM) is a methodology for testing the hypotheses about the means, variances and co-variances of observed data used to develop a structural model depicting the interrelationship of constructs. The structural equation model generally comprises of two parts, one is structural model and another one is measurement model. The structural part represents the interrelationships of latent constructs, whereas the measurement model is the connection of latent constructs to their measured variables by confirmatory model (Joreskog, 1973; Hair et al., 2010). This study uses maximum likelihood (ML) estimation method for hypotheses testing for constructing the relationship model using success factors of teamwork culture and NPD team's capability for NPD success of the firm as well as their indicators by utilizing the theoretical background from the previous literatures as well as the practical data collected from the engineering experts of the firm. The estimation method of hypotheses testing is followed by the adequate fitness tests which are required to be carried out for testing the viability of the assumptions about the interactions of the latent variables. As, the identification of the projected samples required for analysing the assumptions set from the literatures and practical experience is one of the essential criteria of success for the empirical research to test the assumed hypotheses, the necessity of the reliability testing of the collected data is very much vital for performing analysis. After testing of the sample data, the estimation of measurement and structural model is performed using SEM approach.

\subsection{Sample and data collection}

A semi-structured questionnaire has been developed for accumulating data from 380 experts of manufacturing companies in India of various parts of India such as eastern, western, northern and southern parts maximum by visiting and direct interviewing and few over telephonic interviews and e-mails sharing. A pilot study has been conducted in the eastern part of India, mainly in Kolkata and Howrah districts. Finally, the questionnaire is modified based to the valuable suggestions of the experts from manufacturing industries to avoid any misleading results and conclusions (Schwarz \& Oyserman, 2001).

Table 1

Demographic Profile of Respondents

\begin{tabular}{|c|c|c|c|}
\hline Sample Characteristic & Classifications & Total & Percentage \\
\hline Geographical Location & Indian Manufacturing Companies & 263 & 100 \\
\hline \multirow[t]{11}{*}{ Organization Type } & Fabrication & 46 & 17.49 \\
\hline & Electrical equipment & 33 & 12.55 \\
\hline & Industrial valves & 32 & 12.17 \\
\hline & Textile Machineries & 27 & 10.27 \\
\hline & Fire fighting equipment & 26 & 9.89 \\
\hline & Hydraulics \& pneumatic & 25 & 9.50 \\
\hline & Burners and heaters & 22 & 8.37 \\
\hline & Material handling equipment & 21 & 7.98 \\
\hline & Cell and battery & 14 & 5.32 \\
\hline & R\&D sectors & 9 & 3.42 \\
\hline & Air ventilators & 8 & 3.04 \\
\hline \multirow[t]{5}{*}{ Respondent's Profile } & Executive & 69 & 26.23 \\
\hline & Manager & 83 & 31.56 \\
\hline & Senior Manager & 48 & 18.25 \\
\hline & Vice President & 36 & 13.69 \\
\hline & President & 27 & 10.27 \\
\hline \multirow[t]{3}{*}{ Respondent's experience } & $0-5$ years & 87 & 33.08 \\
\hline & $6-10$ years & 65 & 24.71 \\
\hline & $>10$ years & 111 & 42.21 \\
\hline
\end{tabular}


Mostly, the Directors, Vice Presidents and Managers of design \& development departments are considered as right persons to be questioned to ensure the definite responses as their knowledge and experience are helpful and equally dependable for future analysis. Finally, 263 responses among the total data have been considered reliable for final analysis as $78.16 \%$ of total sample delivers response to the request among those $69.21 \%$ is reliable and usable. At the same time, the observation to variable ratio is more than 5 which is quite acceptable for SEM analysis (Fabrigar et al., 2010; MacCallum et al., 1999; Gorsuch, 1983). Profiles of the reliable respondents utilizable for this study have been mentioned in Table 1.

\section{Empirical results}

\subsection{Analysis of measurement validity}

A thorough data survey has been performed in Indian manufacturing industries as per the questionnaire. The manifests are associated with their respective constructs to avoid any confusion. These indicators are segmented in two sections as importance to measure the significance of the manifests for measuring the construct and implementation to quantify the rate of the application of these indicators in practical situation to achieve the teamwork culture. This section of the questionnaire is kept closed to prevent violation of the relationships. A 7 point Likert scale is used to quantify the degree of importance and implementation of the indicators as per the experts' opinions. In case of importance, 1 denotes strongly disagree and 7 denotes strongly agree about the importance of the indicators whereas, in case of implementation of the indicators, 1 denotes very low and 7 denotes very high degree of implementation and the same holds in the case of the NPD team's capability. There are also an open end field provided for suggesting additional indicators of constructs of teamwork culture practices and their importance and implementation are also mentioned, adding novelty by compacting the minute information. The reliability testing of the survey data is performed by composite reliability (CR), average variance extracted (AVE), Cronbach's Alpha reliability testing using IBM SPSS 21.0 software. The reliability index portrays the reliability as well as internal consistency of the collected data sample. The CR values greater than 0.5 is considered as highly reliable whereas its value between 0.3 and 0.5 is moderate. For AVE, values greater than 0.5 indicate the reliability (Holmes \& Smith, 2001). In case of $\alpha$, values either greater or equals to 0.8 is treated as reliable one and can be further used for analysis purpose (Ong et al., 2004; Nunnally, 1978). The list of constructs of teamwork culture and NPD team's capability for NPD success associated with their indicators along with their standardized regression weights (SRW) have been enlisted in Table 2 which also incorporates the reliability indices (CR, AVE and $\alpha$ ) as well. The interview protocol with the description of latent constructs has been detailed in Appendix 1 for better understanding. The structured model depicting the interrelationships of success factors of teamwork culture and their impacts on NPD team's capability for NPD success in terms of technological developments has been analyzed by SEM approach using IBM SPSS AMOS 21.0 software packages.

\subsection{Measurement model results}

Confirmatory factor analysis has been performed for estimating the standardized regression weights (SRWs) of individual manifest variables and the model fit. The crucial step of SEM is the estimation of path values for analyzing the model fitness. Besides, there are multiple methods of assessing the model fitness such as chi-square including degree of freedom (Hu \& Bentler, 1995), goodness-of-fit (GFI), adjusted-goodness-of-fit (AGFI) and root mean square of error approximation (RMSEA) (Bentler, 1990; Chen, 2015). As per the fitness test the model fitting values are within the desired range as $\chi 2=488.598$, degrees of freedom $=242, \chi 2$ /degrees of freedom $=2.019, \mathrm{RMSEA}=0.052, \mathrm{GFI}=0.864, \mathrm{AGFI}=0.836$ (Hair et al., 2010). The SRWs of the manifests of the input and output constructs range from 0.31 to 0.93 as listed in Table 2. Values of reliability indices such as CR and AVE values range from 0.729 to 0.910 and 0.45 to 0.68 . Again another vital reliability index $\alpha$ values range from 0.748 to 0.967 , mostly greater than 0.8 , depicts the satisfactory data reliability for future analysis. 
Table 2

List of latent constructs along with their manifest variables including regression weights and reliability indices

\begin{tabular}{|c|c|c|c|c|c|}
\hline Latent Constructs & $\begin{array}{l}\text { Manifest } \\
\text { Variables }\end{array}$ & SRWs & $\mathrm{CR}$ & AVE & $\alpha$ \\
\hline $\begin{array}{l}\text { Concurrent engi- } \\
\text { neering team } \\
\quad(\mathrm{CET})\end{array}$ & $\begin{array}{l}\mathrm{m} 1 \text { : Collaborative culture } \\
\mathrm{m} 2 \text { : Knowledge integration } \\
\mathrm{m} 3 \text { : Early stage involvement of functional groups } \\
\mathrm{m} 4 \text { : Early stage manufacturing activities } \\
\text { m5: Concurrency of process and product design in } \\
\text { same group } \\
\text { m6: Concurrency of process and product design in dif- } \\
\text { ferent groups } \\
\text { m7: Sharing of information } \\
\text { m8: Idea generation and sharing } \\
\text { m9: Coordination to achieve the target } \\
\text { m10: Strategic consideration }\end{array}$ & $\begin{array}{l}0.48 \\
0.34 \\
0.39 \\
0.73 \\
0.61 \\
0.49 \\
0.74 \\
0.51 \\
0.43 \\
0.60 \\
\end{array}$ & 0.72 & 0.45 & 0.748 \\
\hline Latent Constructs & $\begin{array}{c}\text { Manifest } \\
\text { Variables }\end{array}$ & SRWs & $\mathrm{CR}$ & AVE & $\alpha$ \\
\hline $\begin{array}{l}\text { Concurrent engi- } \\
\text { neering team } \\
\text { (CET) }\end{array}$ & $\begin{array}{l}\text { m11: Inter department opinion sharing } \\
\text { m12: Solving disagreements } \\
\text { m13: Managerial support and motivation }\end{array}$ & $\begin{array}{l}0.53 \\
0.82 \\
0.64\end{array}$ & & & \\
\hline $\begin{array}{l}\text { Communication In- } \\
\text { frastructure } \\
\text { CI) }\end{array}$ & $\begin{array}{l}\text { m14: Regular meeting for problem-solving } \\
\text { m15: Virtual communication } \\
\text { m16: Video conference } \\
\text { m17: NPD database system } \\
\text { m18:Internet-based telecommunication tools } \\
\text { m19: Face-to-face meetings in between virtual } \\
\text { teams }\end{array}$ & $\begin{array}{l}0.74 \\
0.57 \\
0.82 \\
0.76 \\
0.93 \\
0.86\end{array}$ & 0.78 & 0.47 & 0.801 \\
\hline $\begin{array}{l}\text { System Integration } \\
\text { (SI) }\end{array}$ & $\begin{array}{l}\text { m20: Formal department for system integration } \\
\mathrm{m} 21 \text { : Experienced engineers for system integration } \\
\mathrm{m} 22 \text { :Availability of middle management } \\
\mathrm{m} 23 \text { : Presence of a product manager for system inte- } \\
\text { gration }\end{array}$ & $\begin{array}{l}0.58 \\
0.80 \\
0.73 \\
0.61\end{array}$ & 0.79 & 0.52 & 0.838 \\
\hline $\begin{array}{l}\text { Result Orientation } \\
\text { (RO) }\end{array}$ & $\begin{array}{l}\text { m24:Interrelationships of time, costs, quality, peo- } \\
\text { ple and organization } \\
\text { m25: Consideration of different times associated } \\
\text { m26: Consideration of various cost associated } \\
\text { m27: Focus on quality factors } \\
\text { m28: Consideration of factors related to people } \\
\text { m29: Accumulation of both financial and non-fi- } \\
\text { nancial results }\end{array}$ & $\begin{array}{l}0.42 \\
0.71 \\
0.63 \\
0.34 \\
0.87 \\
0.83\end{array}$ & 0.91 & 0.68 & 0.967 \\
\hline $\begin{array}{l}\text { NPD Team's Capa- } \\
\text { bility }\end{array}$ & $\begin{array}{l}\text { m30: Technological developments } \\
\text { m31: Expansion of product family } \\
\text { m32: Scheduled product launching frequency } \\
\text { m33: Reduction of failure rate }\end{array}$ & $\begin{array}{l}0.79 \\
0.36 \\
0.71 \\
0.31\end{array}$ & 0.91 & 0.68 & 0.913 \\
\hline
\end{tabular}

Notes:

[Maximum-likelihood method has been used to estimate the measurement models

Model Fit Indices: Ratio of $\chi^{2}$ to degrees of freedom $=2.019$, RMSEA $=0.052, \mathrm{GFI}=0.864$, AGFI $=0.836$.]

The validation of the occurrence of manifest variables on their respective latent construct has been performed using confirmatory factor analysis for both input and output measurement models. In case of input measurement model, concurrent engineering team (CET), communication infrastructure (CI), system integration (SI) and result orientation (RO) have been treated as latent constructs while in output measurement model, NPD Team's Capability as output construct. CET is quantified by collaborative culture among the team, knowledge integration among various teams within the organization, early stage involvement of functional groups, early stage manufacturing activities, concurrency of process and product design in same group, concurrency of process and product design in different groups, information 
sharing, idea generation and sharing, coordination to achieve the target, strategic consideration, interdepartment opinion sharing, solving disagreements and support and motivation from top management. In case of communication infrastructure $(\mathrm{CI})$, meeting on the regular basis for problem solving, virtual communication, video conference, NPD database system, internet-based telecommunication tools and face-to-face meetings in between virtual teams are used to measure the communication practice in the organization. For SI, availability of formal department for system integration, number of experienced engineers, availability of middle management and presence of a product manager for system integration make this practice feasible to measure in the practical scenario. The RO among the teams are measured by interrelationships of time, costs, quality, people and organization, consideration of different times associated, consideration of various cost associated, focus on quality factors, consideration of factors related to people and accumulation of both financial and non-financial results. Like input constructs, the output construct which is NPD team's capability is quantified by technological developments, expansion of product family, scheduled product launching frequency and reduction of failure rate. The SRWs i.e. the loading values obtained from the maximum-likelihood method are all positive and mostly greater than 0.45 (Hair et al., 2009). Few of them are less than 0.45 but those can be considerable to develop the measurement model for both input and output constructs. These SRWs along with the values of CR, AVE and $\alpha$ for measuring the composite reliability, convergent validity and internal consistency of each construct respectively are listed in Table 2 . This shows that values of CR, AVE and $\alpha$ are within the acceptable range to use the empirical data for future analysis.

\subsection{Structural Model Results}

Analysis of measurement model is followed by the structural model formation. In case of structural model also the fitness tests are performed showing the appropriate model-to-data fit as $\chi 2=474.39$, degrees of freedom $=251, \chi 2$ /degrees of freedom $=1.89, \mathrm{RMSEA}=0.047, \mathrm{GFI}=0.891, \mathrm{AGFI}=0.847$ (Hair et al., 2010). The structural model representing the hypothesized relationships between constituents of teamwork culture as input constructs and NPD team's capability as output construct and their indicators developed by using IBM SPSS AMOS 21.0 software is shown in Fig. 2.Most of the path estimates between the constructs for both input and output ranges from 0.38 to 0.69 depicting that proposed hypotheses are supported. Only one path estimate is showing negative value as -0.04 which depicts the assumed hypothesis unsupported. The values of path estimates are listed in Table 3.

Table 3

Statistics of Path Estimates obtained from Structural Model

\begin{tabular}{lcc}
\hline \multicolumn{1}{c}{ Path Description } & Hypotheses & Standardized Coefficient \\
\hline CET $\rightarrow$ NPD Team's Capability & H1a & $0.80(* * *)$ \\
CET $\rightarrow$ RO & H1b & $0.58(* * *)$ \\
CI $\rightarrow$ NPD Team's Capability & H2a & $0.48(* * *)$ \\
\hline Path Description & Hypotheses & Standardized Coefficient \\
CI $\rightarrow$ CET & H2b & $0.69(* * *)$ \\
SI $\rightarrow$ NPD Team's Capability & H3a & $0.39(* * *)$ \\
SI $\rightarrow$ CET & H3b & $0.38(* * *)$ \\
SI $\rightarrow$ RO & H3c & $-0.04(\mathrm{n} . \mathrm{s})$ \\
RO $\rightarrow$ NPD Team's Capability & H4 & $0.43(* * *)$ \\
\hline $\begin{array}{l}\text { Notes: } \\
{[* * * \text { indicates the significance at p value }<0.001}\end{array}$ & & \\
n.s. stands for not significant & & \\
Model Fit Indices: Ratio of $\chi^{2}$ to degrees of freedom $=1.89$, RMSEA $=0.047$, GFI $=0.891$, AGFI $\left.=0.847.\right]$ &
\end{tabular}

Structural model represents the interrelationship among the latent constructs for analyzing the hypotheses among the constructs developed from the available literatures. The path values among the constructs are calculated by multiple regression analysis using SEM. The results of structural model are exhibited in Table 3 which explains the relationship among the constructs as per developed hypotheses. The concurrent engineering team (CET), communication infrastructure (CI), system integration (SI) and result orientation (RO) positively influence the NPD team's capability as the path values between them are positive such as $0.80,0.48,0.39$ and 0.43 , respectively. The CET is escalated by CI and SI as obtained from 
the standardized coefficients of path estimates such as 0.69 and 0.38 , respectively. Again CET positively motivates RO as depicted by the path estimates between them is 0.58. But in case of effect of SI on RO, the Table 3 shows that path estimates between them is -0.04 which is not significant. That means there is no positive relationship in between SI and $\mathrm{RO}$ which depicts that the developed hypothesis in between $\mathrm{SI}$ and RO is proven insignificant.

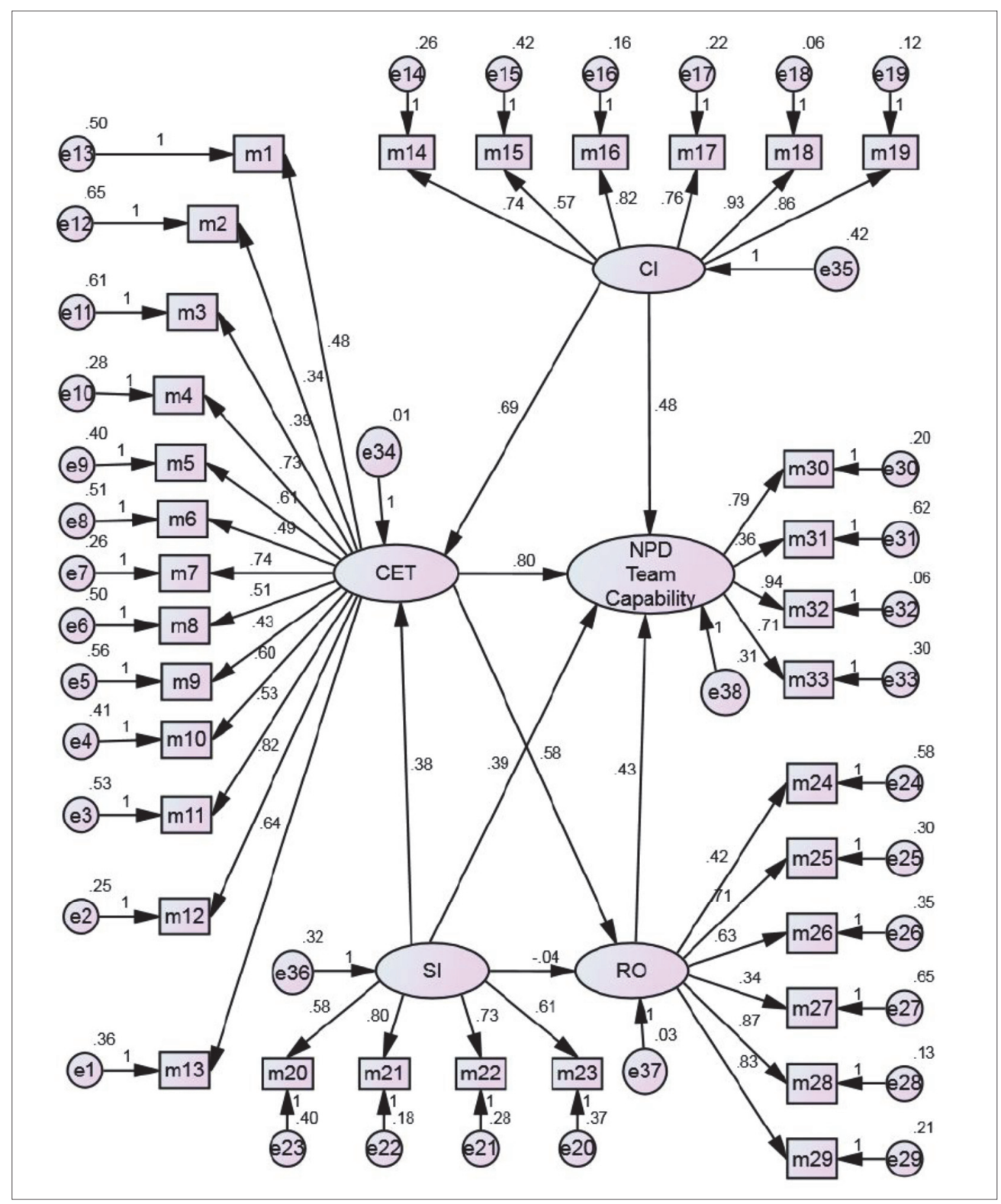

Fig. 2. Structural Equation Modeling (SEM) model after execution portraying the combined impact of teamwork and its associated factors on NPD team's capability

The Fig. 2, is developed on the basis of the path model shown in Fig. 1, consisting of both measurement model as well as structural model combining the input and output latent constructs and their measures. This model represents the regression weights of manifest variables to quantify the latent constructs as shown in Table 2 and the standardized path coefficients that are the path estimates as shown in Table 3. The values in between the constructs and their indicators are fixed at 1.0 initially. There is error term associated with each manifest variable and also with each latent construct. The difference between the actual values and the desired values are calculated by the error terms associated with each indicator. Along with the values, the direction of the arrow heads is also crucial for complete significance of the 
framework. The arrow heading from one construct to another depicts the impact of those particular factors on the construct to which the arrow is directed.

\section{Conclusion}

This study has identified the success factors of teamwork culture used to influence the NPD team's capability for successful NPD. Firstly, it recognized CET as a crucial factor of teamwork culture which is an approach where various functional groups both internal and external work together to develop new products uninterruptedly by sharing ideas and information as well as solving problem together by overcoming the differences. This CET again is controlled by the CI among the individual team members. A better communication practice not only enriches the CET culture but also contributes to NPD team's capability for technological developments by generating the common decision making culture in the organization. CET again influences the RO of the firm for accumulating and interrelating time, cost, quality, people and organization for NPD team's capability. The integration of all the processes under the system is termed as SI which escalates the CET culture as well as NPD team's capability for NPD success by integrating all kinds of available resources, like qualities, innovative ideas, of various functional teams. This integrating quality accelerates the CET culture by providing all possible resources for development which is essential for concurrent work flow. Finally, RO is another factor of teamwork culture which practically depicts the strategic orientation which controls the NPD team's capability of the firm by strategically integrating the individual results of all processes. But the analysis from the developed structural model shows that RO is not positively influenced by SI which depicts that assumed interrelationship of SI on RO is unsupported. This study identifies the teamwork as an organizational culture helps to structure the roadmap for selection, development and support the appropriate innovative ideas for engineers while merging the non-technical parameters to pure technical parameters in technological developments and necessarily is considered as an important issue in engineering studies. The association of teamwork culture for technological developments enriches the NPD team's capability supporting the vitality of small team culture for NPD success.

The main aim of the teamwork is to develop high-tech products within scheduled time to avoid the cost overrun. Technological developments within scheduled time have been used as a measure for the NPD team's capability for NPD success that obviates time overrun. Organization should be concerned about the break-even-time of the newly developed product and try to expand the product family for generating better profit and ultimate success, while they also need to be careful about the consistency of scheduled product launching frequency by ensuring lowered rate of product failure.

The developed interrelationship model clearly realizes the significance of the teamwork culture within the organization for creating innovative ideas and fulfilling those ideas by providing a suitable atmosphere fostering the NPD team's capability for NPD success in terms of technological developments within scheduled time ensuring organizational success.

\section{Acknowledgements}

The research work was substantially supported by a grant from the Department of Science and Technology (DST) of India as a DST INSPIRE Fellowship to the DST INSPIRE Fellow of IF 130426. The authors are also grateful to the industry personnel and experts who shared their opinions and suggestions for completing this research work.

\section{References}

Anthony, E. L., Green S. G., \& McComb, S. A. (2014). Crossing functions above the cross-functional project team: The value of lateral coordination among functional department heads. Journal of Engineering and Technology Management, 31, 141-158. 
Aronson, Z. H., Reilly, R. R., \& Lynn, G. S. (2006). The impact of leader personality on new product development teamwork and performance: The moderating role of uncertainty. Journal of Engineering and Technology Management, 23(3), 221-247.

Atuahene-Gima, K., Slater, S. F., \& Olson, E. M. (2005). The contingent value of responsive and proactive market orientations for new product program performance. Journal of Product Innovation Management, 22(6), 464-482.

Augusto, M., \& Coelho, F. (2009). Market orientation and new-to-the-world products: exploring the moderating effects of innovativeness, competitive strength, and environmental forces. Industrial Marketing Management, 38(1), 94-108.

Azad, N., Aliakbar, S., Zarifi, S., \& Hozouri, S. (2013). Investigating product development strategy in beverage industry using factor analysis. Management Science Letters, 3(3), 897-902.

Bain, P. G., Mann, L., \& Pirola-Merlo, A. (2001). The innovation imperative: The relationships between team climate, innovation, and performance in research and development teams. Small Group Research, 32(1), 55-73.

Benoliel, P., \& Somech, A. (2015). The role of leader boundary activities in enhancing interdisciplinary team effectiveness. Small Group Research, 46(1), 83-124.

Bentler, P. M. (1990). Comparative fit indexes in structural models. Psychological bulletin, 107(2), 238.

Berthon, P., Hulbert, J., \& Pitt, L. (2004). Innovation or customer orientation? An empirical investigation. European Journal of Marketing, 38(9/10), 1065-1090.

Chen, H. C. (2015). The impact of children's physical fitness on peer relations and self-esteem in school settings. Child Indicators Research, 1-16.

Chen, C. Y., Chen, P. C., \& Lu, Y. E. (2013). The coordination processes and dynamics within the inter-organizational context of contract-based outsourced engineering projects. Journal of Engineering and Technology Management, 30(2), 113-135.

Chen, C. J., Liu, T. C., Chu, M. A., \& Hsiao, Y. C. (2014). Intellectual capital and new product development. Journal of Engineering and Technology Management, 33, 154-173.

Choi, H. G., \& Ahn, J. (2010). Risk analysis models and risk degree determination in new product development: A case study. Journal of Engineering and Technology Management, 27(1-2), 110124.

Chou, C., \& Yang, K. P. (2011). The interaction effect of strategic orientations on new product performance in the high-tech industry: A nonlinear model. Technological Forecasting \& Social Change, 78(1), 63-74.

Cleetus, J. (1992). Definition of Concurrent Engineering (Report No. CERC-TR-RN-92-003). West Virginia University: Morgantown, WV.

Crawford, C. M., \& Di Benedetto, C. A. (2000). New Products Management. McGraw-Hill: Boston.

De Sousa Mendes, G. H., \& Miller Devós Ganga, G. (2013). Predicting success in product development: The application of principal component analysis to categorical data and binomial logistic regression. Journal of Technology Management \& Innovation, 8(3), 83-97.

DeVries, R., Van Den Hooff, B., \& de Ridder, J.A. (2006). Explaining knowledge sharing: the role of team communication styles, job satisfaction, and performance beliefs. Communication Research, 33(2), 115-135.

Early, P. C. (2006). Leading Cultural Research in the Future: A Matter of Paradigms and Taste. Journal of International Business Studies, 37(6), 922-931.

Estrada, I., Martin-Cruz, N., \& Pérez-Santana, P. (2013). Multi-partner alliance teams for product innovation: The role of human resource management fit. Innovation, 15(2), 161-169.

Everett, A. M., Wong, Y. Y., Evans, N., \& Tuyet Hong, L. (2002). The influence of Chinese American cultural values on workplace communication, innovation, and teamwork. Innovation, 4(13), 113-128.

Fabrigar, L. R., Porter, R. D., \& Norris, M. E. (2010). Some things you should know about structural equation modeling but never thought to ask. Journal of Consumer Psychology, 20(2), 221-225. 
Felekoglu, B., Maier, A. M., \& Moultrie, J. (2013). Interactions in new product development: How the nature of the NPD process influences interaction between teams and management. Journal of Engineering and Technology Management, 30(4), 384-401.

Friesl, M., Sackmann, S. A., \& Kremser, S. (2011). Knowledge sharing in new organizational entities: The impact of hierarchy, organizational context, micro-politics and suspicion. Cross Cultural Management: An International Journal, 18(1), 71-86.

Frishammar, J., Lichtenthaler, U., \& Kurkkio, M. (2012). The front end in non-assembled product development: A multiple case study of mineral-and metal firms. Journal of Engineering and Technology Management, 29(4), 468-488.

Gemuenden, H. G., \& Lechler, T. (1997). Success factors of project management: the critical fewan empirical investigation. In Innovation in Technology Management-The Key to Global Leadership. PICMET'97: Portland International Conference on Management and Technology (pp. 375-377). IEEE.

Ghauri, P., \& Rosendo-Rios, V. (2016). Organizational cross-cultural differences in the context of innovation-oriented partnerships. Cross Cultural \& Strategic Management, 23(1), 128-157.

Green, S.G., McComb, S.A., \& Compton, W.D. (2000). Promoting effective linkages between crossfunctional project teams and the organization. Advances in the Management of Organizational Quality, 5(1), 29-70.

Gorsuch, R. L. (1983). Factor analysis. Hillsdale, NJ: Lawrence Erlbaum.

Gu, Q., Jiang, W., \& Wang, G. G. (2016). Effects of external and internal sources on innovation performance in Chinese high-tech SMEs: A resource-based perspective. Journal of Engineering and Technology Management, 40, 76-86.

Hailu, H., Mengstu, S., \& Hailu, T. (2018). An integrated continuous improvement model of TPM, TPS and TQM for boosting profitability of manufacturing industries: An innovative model \& guideline. Management Science Letters, 8(1), 33-50.

Hair, J. F., Black, W. C., Babin, B. J., \& Anderson, R. E. (2010). Multivariate Data Analysis: A Global Perspective. Upper Saddle River, NJ: Prentice hall.

Hartmann, A. (2006). The role of organizational culture in motivating innovative behaviour in construction firms. Construction Innovation, 6(3), 159-172.

Hitt, M., Ireland, R.D., \& Lee, H. (2000). Technological learning, knowledge management, firm growth and performance: an introductory essay. Journal of Engineering and Technology Management, 17(3), 231-246.

Hoegl, M., \& Parboteeah, K. P. (2003). Goal setting and team performance in innovative projects: On the moderating role of teamwork quality. Small Group Research, 34(1), 3-19.

Hoegl, M., Parboteeah, K. P., \& Gemuenden, H. G. (2003). When teamwork really matters: task innovativeness as a moderator of the teamwork-performance relationship in software development projects. Journal of Engineering and Technology Management, 20(4), 281-302.

Hoegl, M., \& Parboteeah, K. P. (2007). Creativity in innovative projects: How teamwork matters. Journal of Engineering and Technology Management, 24(1), 148-166.

Holmes, P., \& Smith, P. (2001). Introduction to structural equation modelling using LISREAL. Perth: ACSPRI-Winter training Program.

Hu, L., \& Bentler, P. M. (1998). Fit indices in covariance structure modeling: sensitivity to under parameterized model misspecification. Psychological Methods, 3(4), 424-453.

Johnson, W. H. A., \& Filippini, R. (2013). Integration capabilities as mediator of product development practices-performance. Journal of Engineering and Technology Management, 30(1), 95111.

Joreskog, K. G. (1973). A general method for estimating a linear structural equation system. In: Goldberger A. S, Duncan O D (Eds.) Structural Equation Models in the Social Sciences. Academic Press, New York, pp. 85-112.

Kennedy, D. M., McComb, S. A., \& Vozdolska, R. R. (2011). An investigation of project complexity's influence on team communication using Monte Carlo simulation. Journal of Engineering and Technology Management, 28(3), 109-127. 
Kleinsmann, M., Buijs, J., \& Valkenburg, R. (2010). Understanding the complexity of knowledge integration in collaborative new product development teams: a case study. Journal of Engineering and Technology Management, 27(1), 20-32.

Leitner, K.H. (2011). The effect of intellectual capital on product innovativeness in SMEs. International Journal of Technology Management, 53(1), 1-18.

Lindstrom, V., \& Winroth, M. (2010). Aligning manufacturing strategy and levels of automation: A case study. Journal of Engineering and Technology Management, 27(3), 148-159.

MacCallum, R. C., Widaman, K. F., Shang, S., \& Hong, S. (1999). Sample size in factor analysis. Psychological Methods, 4(1), 84-99.

Mazzarol, T. (2002). Innovativeness in small firms: An exploratory study of the perspectives of growth oriented owner-managers. Innovation, 4(1-3), 30-40.

Mousavi, S., \& Darvishi, Z. (2014). A study on new market development using a hybrid of QFD and ANP. Management Science Letters, 4(7), 1455-1458.

Nagano, M. S., Stefanovitz, J. P., \& Vick, T. E. (2014). Innovation management processes, their internal organizational elements and contextual factors: An investigation in Brazil. Journal of Engineering and Technology Management, 33, 63-92.

Nihtilä, J. (1999). R\&D-Production integration in the early phases of new product development projects. Journal of Engineering and Technology Management, 16(1), 55-81.

Nikakhtar, H., Aghamousa, R., \& Meshkani, F. (2014). The role of empowering organization capabilities on efficiency of new product development. Management Science Letters, 4(3), 443-446.

Nunnally, J. C. (1978). Psychometric Theory. McGraw Hill, New York.

Ong, C. S., Lai, J. Y., \& Wang, Y. S. (2004). Factors affecting engineers' acceptance of asynchronous e-learning systems in high-tech companies. Information and Management, 41(6), 795-804.

O'Sullivan, A. (2003). Dispersed collaboration in a multi-firm, multi-team product-development project. Journal of Engineering and Technology Management, 20(1), 93-116.

Parthasarthy, R., \& Hammond, J. (2002). Product innovation input and outcome: moderating effects of the innovation process. Journal of Engineering and Technology Management, 19(1), 75-91.

Poole, M., \& Hirokawa, R. (1996). Introduction: communication and group decision making. In: Hirokawa, R., Poole, M. (Eds.), Communication and Group Decision Making. Sage, Thousand Oaks, CA, pp. 3-18.

Rodríguez-Pinto, J., Rodríguez-Escudero, A. I., \& Gutiérrez-Cillán, J. (2012). How market entry order mediates the influence of firm resources on new product performance. Journal of Engineering and Technology Management, 29(2), 241-264.

Rousseau, V., Aubé, C., \& Savoie, A. (2006). Teamwork behaviors: A review and an integration of framework. Small group research, 37(5), 540-570.

Saji, B. S. (2004). Workforce diversity, temporal dimensions and team performance. Cross Cultural Management: An International Journal, 11(4), 40-59.

Schwarz, N., \& Oyserman, D. (2001). Asking questions about behavior: Cognition, communication, and questionnaire construction. American Journal of Evaluation, 22(2), 127-160.

Song, Y. I., Lee, D. H., Lee, Y. G., \& Chung, Y. C. (2007). Managing uncertainty and ambiguity in frontier R\&D projects: A Korean case study. Journal of Engineering and Technology Management, 24(3), 231-250.

Strubler, D. C., \& York, K. M. (2007). An exploratory study of the team characteristics model using organizational teams. Small Group Research, 38(6), 670-695.

Sun, H., Wong, S. Y., Zhao, Y., \& Yam, R. (2012). A systematic model for assessing innovation competence of Hong Kong/China manufacturing companies: A case study. Journal of Engineering and Technology Management, 29(4), 546-565.

Tsai, K. H., Hsieh, M. H., \& Hultink, E. J. (2011). External technology acquisition and product innovativeness: The moderating roles of $\mathrm{R} \& \mathrm{D}$ investment and configurational context. Journal of Engineering and Technology Management, 28(3), 184-200.

Tushman, M., \& Anderson, P. (1997). Managing Strategic Innovation and Change. Oxford University Press, Oxford: 3-23. 
Varner, I., \& Beamer, L. (2005). Intercultural Communication in the Global Workplace. New York: McGraw-Hill.

Willaert, S. S., De Graaf, R., \& Minderhoud, S. (1998). Collaborative engineering: A case study of Concurrent Engineering in a wider context. Journal of Engineering and Technology Management, 15(1), 87-109.

\section{Appendix A. Interview Protocol with description of latent variables}

Latent variables and description of their manifests of teamwork as organizational culture:

\section{Cross-functional team:}

- Collaborative culture (m1): Company culture of working together of innovative product development project team, marketing, R\&D and manufacturing department as a collaborative team

- Knowledge integration (m2): Integration of technological knowledge and marketing knowledge for innovative product development

- Early stage involvement of functional groups (m3): Involvement of various discipline from early stages of new product development

- Early stage manufacturing activities (m4): Occurrence of manufacturing activities from early stages of product development

- Concurrency of process and product design in same group (m5): Degree of process design is done concurrently with product design

- Concurrency of process and product design in different groups (m6): Designs of product and process development are established concurrently by a group of employees from various disciplines

- Sharing of information (m7): Sharing of information among different departments

- Idea generation and sharing (m8): Degree of operation in generating new product ideas and sharing information

- Co-ordination to achieve targets (m9): Willingness to coordinate to achieve the target of innovative product development

- Strategic consideration (m10): Willingness to coordinate for strategic consideration

- Inter department opinion sharing (m11): Sharing of information among different product development groups

- Solving disagreements (m12): Degree of exchanging complete and accurate information for problem-solving

- Managerial support and motivation (m13): Degree of motivation and support of top managers

\section{Communication:}

- Regular meeting for problem solving (m14):Arrangement of direct, face-to-face meetings and problem solving between co-located teams (almost every day) 
- Virtual communication (m15): Availability of E-mail, messenger, shared database supporting face-to-face communications (on a continuous base) facilities in your company

- Video conference (m16): Regular video conferencing (on average 10-20 times for the entire NPD process) between virtual teams are arranged in your company

- NPD database system (m17): Usage of NPD database system is available on a continuous base in your company

- Internet-based telecommunication tools (m18): Availabilities of internet-based telecommunication tools for the file sharing on-line real-time communications in your company on a continuous base

- Face-to-face meeting of virtual teams (m19): Irregular face-to-face meetings in between virtual teams are arranged in your company for periodic adjustments (typically, 1-2 times per project)

\section{System Integration:}

- Formal department for system integration (m20): Availability of formal department that manages the system integration

- Experienced engineers for system integration (m21): Possession of experienced engineers with product knowledge in the system integration department who help to integrate several teams working on separate modules

- Availability of middle management (m22): Availability of middle management, with operational skills and understanding of corporate strategy, to handle system integration activities

- Presence of a product manager for system integration (m23): Necessity of a product manager for system integration

4. Result Orientation (RO) [CR=0.91; $A V E=0.68 ; \alpha=0.967]$

- Interrelationships of time, costs, quality, people and organization (m24): Interrelationships among various backgrounds like time, costs, quality, people and organization for better innovative product development activity

- Consideration of different times associated (m25): In case of time, consideration of time for idea generation, speed, cycle time and delivery time

- Consideration of various cost associated(m26):In case of costs, consideration of operations cost and cost savings

- Focus on quality factors (m27): Focus on customer satisfaction, service, reliability and safety for quality purpose

- Consideration of factors related to people and market (m28): In case of people, use of teaching, appreciation and involvement as sub factors and for market concern about revenue, market shares, status, organizational knowledge and change in culture for result orientation

- Accumulation of both financial and non-financial results (m29):Overall, accumulation of both financial and non-financial results together for result orientation purpose

5. NPD Team's Capability [CR=0.91; $A V E=0.68 ; \alpha=0.967]$ 
- Technological developments (m30): Concern about the idea of break-even-time and technological breakthrough to beat the competition technologically

- Expansion of product family (m31): Expansion of product family by innovating different added features to the existing products and introduce them to the market in proper time to reduce the cannibalization effect which means the obsolescence of their own products due to introduction of new one by themselves

- Scheduled product launching frequency (m32): Sustain frequency of new product launching time to maintain the launch-on-time by controlling the development time of products

- Reduction of failure rate (m33): Reduction of risks which helps to decrease the failure rate of the developed products

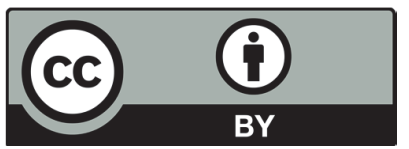

(C) 2018 by the authors; licensee Growing Science, Canada. This is an open access article distributed under the terms and conditions of the Creative Commons Attribution (CCBY) license (http://creativecommons.org/licenses/by/4.0/). 